\title{
Late post-pump blood flow obstruction in a novel left ventricular assist device: The unusual case of a twisted outflow graft
}

Thomas Grüger, MD, ${ }^{\mathrm{a}}$ Friedrich Kaufmann, DiplEng, ${ }^{\mathrm{a}}$ Stephan Dreysse, MD, ${ }^{\mathrm{a}}$ Volkmar Falk, MD, PhD, ${ }^{\mathrm{a}, \mathrm{b}, \mathrm{c}}$ Thomas Krabatsch, MD, PhD, ${ }^{\mathrm{a}, \mathrm{b}}$ and Evgenij Potapov, MD, PhD, ${ }^{\mathrm{a}, \mathrm{b}}$ Berlin, Germany

From the ${ }^{\mathrm{a} G e r m a n}$ Heart Center Berlin, Berlin, Germany; ${ }^{\mathrm{b}} \mathrm{DZHK}$ (German Centre for Cardiovascular Research), Partner Site, Berlin, Germany; and ${ }^{\mathrm{c}}$ Department of Cardiovascular Surgery, Charité - Universitätsmedizin, Berlin, Germany.

Disclosures: Authors have nothing to disclose with regard to commercial support.

Received for publication May 18, 2017; revisions received July 17, 2017; accepted for publication Aug 7, 2017; available ahead of print Sept 26, 2017.

Address for reprints: Evgenij Potapov, MD, PhD, Department of Cardiothoracic and Vascular Surgery, German Heart Center Berlin, Augustenburger Platz 1, 13353 Berlin, Germany (E-mail: potapov@dhzb.de).

J Thorac Cardiovasc Surg 2018;155:e33-5

$0022-5223 / \$ 36.00$

Copyright (C) 2017 by The American Association for Thoracic Surgery

http://dx.doi.org/10.1016/j.jtcvs.2017.08.022

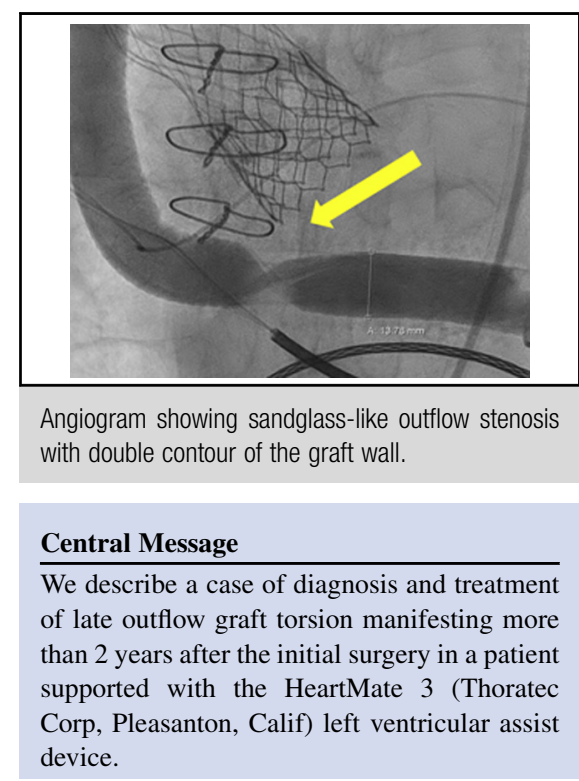

See Editorial Commentaries pages e 37 and e39.
One of the life-threatening complications in patients treated with a left ventricular assist device is obstruction of the blood flow through the pump. ${ }^{1,2}$ When an obstruction

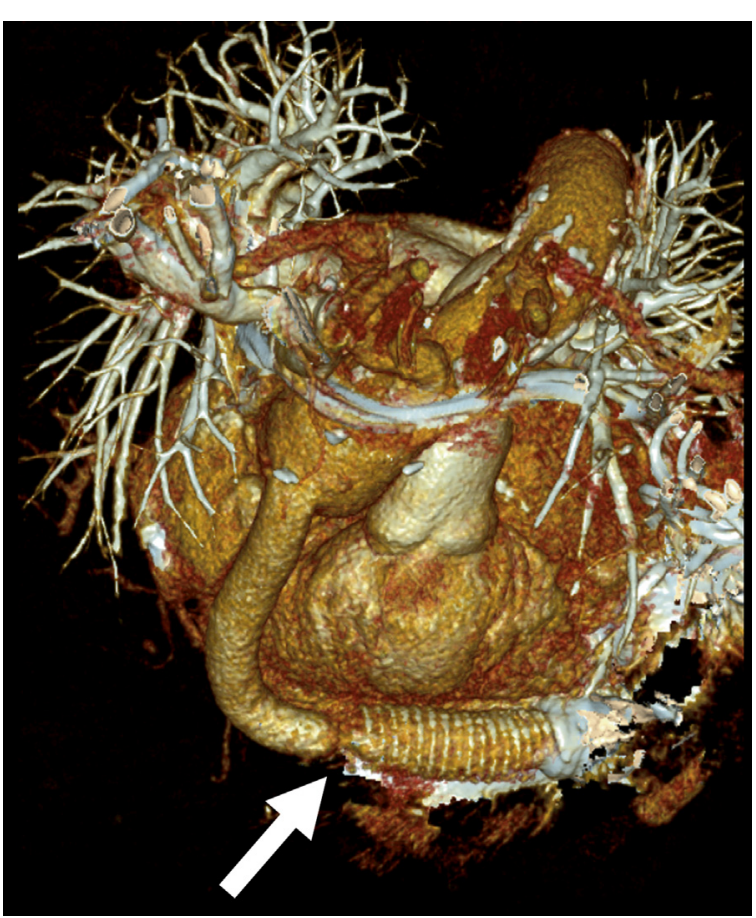

FIGURE 1. CT scan showing sandglass-like outflow graft stenosis (arrow) before stent implantation.

Video clip is available online. occurs, recognition of the type of obstruction and appropriate treatment are important for outcome.

\section{CASE REPORT}

A 72-year-old patient with dilative cardiomyopathy (Intermacs level 3) received implantation of the HeartMate 3 (Thoratec Corp, Pleasanton, Calif) through a median sternotomy using cardiopulmonary bypass with visual control of the position of the outflow graft and the bend relief. After a complication-free period of 2 years and 1 month, the patient was admitted with symptoms of heart failure and an abrupt decrease of pump flow to 2.6 to $3 \mathrm{~L} / \mathrm{min}$ at $5700 \mathrm{rpm}$ pump speed over several days. The internal trendline parameter of "rotor noise," which describes vibrations of the impeller, simultaneously increased by $30 \%$. The left ventricle was enlarged to up to $7 \mathrm{~cm}$ with opening of the aortic valve. Computed tomography (CT) scanning revealed severe stenosis of the outflow graft at the end of the bend relief (Figure 1). The next day, angiography was performed with a reduced pump speed of $4000 \mathrm{rpm}$ to reduce dilution of the contrast (Figure 2 and Video 1), and a 14/35 stent was implanted using the Sentinel system 


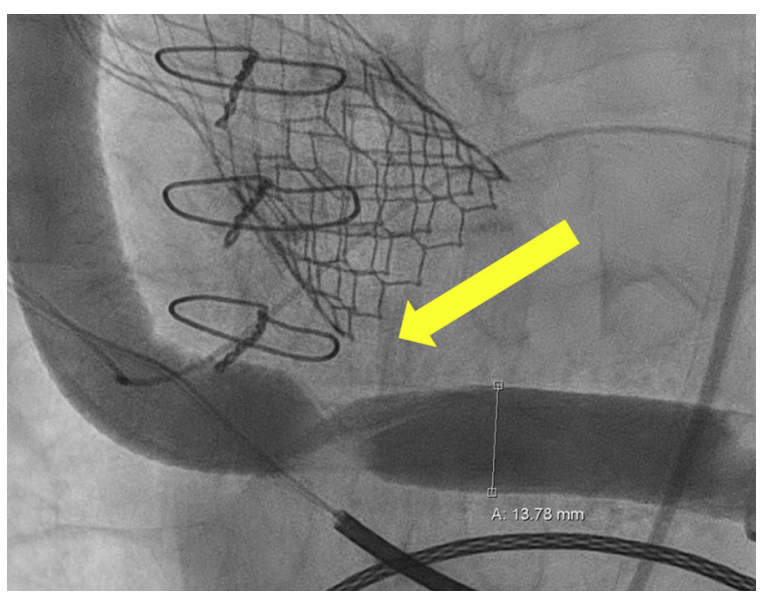

FIGURE 2. Angiogram showing sandglass-like outflow graft stenosis (yellow arrow) with double contour of the graft wall.

(Claret Medical, Inc, Santa Rosa, Calif) ${ }^{3}$ for carotid protection, under the assumption of outflow graft thrombosis but no improvement in the pump flow was achieved. The procedure was being performed in a hybrid operating room and under intubation. The patient was then turned slightly to the right side, and a left anterior thoracotomy was performed in the sixth intercostal space under the assumption of graft torsion. The tissue around the pump and the outflow graft was dissected; the bend relief, which was correctly connected, was longitudinally opened at its plastic part and a circular transection was made close to its metal part with the snap mechanism. The outflow graft was found to be distorted (Figure 3,A) counterclockwise looking from the pump in the direction of flow. Rotation without loosening of the nut of approximately $80^{\circ}$ to $110^{\circ}$ (Figure $3, B$ ) normalized the graft alignment, and pump flow increased to $5.5 \mathrm{~L} /$ min. Before the wound was closed, the outflow graft was

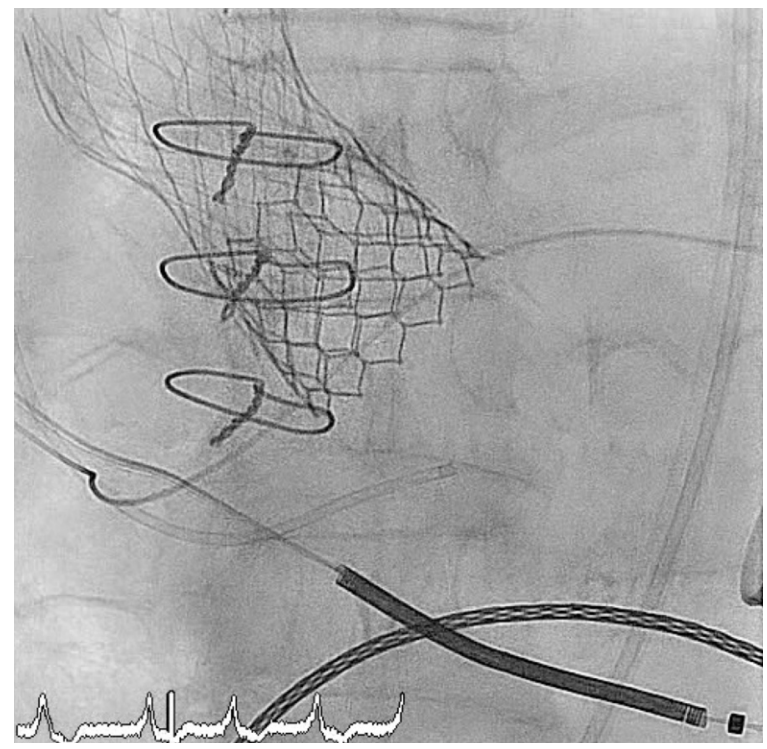

VIDEO 1. The catheter was introduced retrogradely from the ascending aorta and passed behind the twisting. The pump speed was slowed down to $4000 \mathrm{rpm}$, resulting in a pump flow of less than $3 \mathrm{~L} / \mathrm{min}$, and contrast medium was injected. The angiogram shows sandglass-like outflow graft stenosis with double contour of the graft wall. Video available at: http:// www.jtcvsonline.org/article/S0022-5223(17)31779-8/fulltext.

protected by wrapping with a $5-\mathrm{cm}-$ long piece of a $20-\mathrm{mm}$ ring reinforced polytetrafluoroethylene (Gore-Tex, WL Gore \& Associates Inc, Flagstaff, Ariz) graft. The patient was discharged home 1 week later.

\section{DISCUSSION}

In the present case, the torsion of the outflow graft was diagnosed more than 2 years after surgery. Retrospectively, it is not possible to define the time point of the torsion.

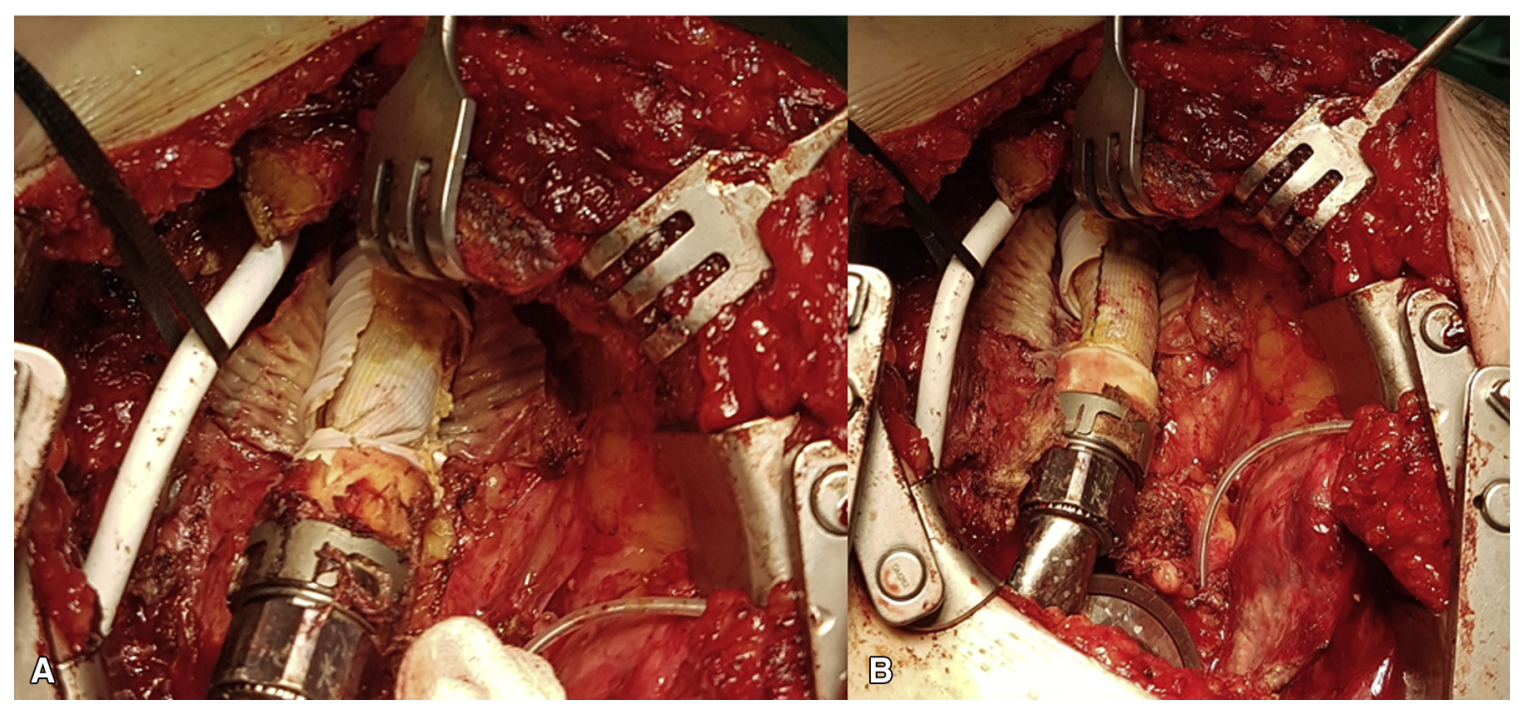

FIGURE 3. A, Intraoperative view of the twisted graft after opening of the kinking protector. B, The same view after rotation of the graft into the correct position. 
Speaking against intraoperative twisting are the 2-year event-free period with pump flow of over $5 \mathrm{~L} / \mathrm{min}$ and the rapid onset of the symptoms and flow decrease. However, the fairly tightly screwed nut, as ascertained during the revision, would have made gradual rotation of the graft after surgery unlikely, but not impossible, because the graft alignment was corrected without loosening the nut. What remains unclear is whether there could have been gradual rotation that might have occurred because of flow characteristics (abrupt changes in the pump speed 30 times per minute) or cardiac pulsation, that over time might have caused rotation of the graft, even though the nut was tightly secured.

It may also be speculated that the twist could have been produced during implantation but have been spread over the whole length of the graft, thus not causing significant stenosis. Over time, fibrin deposits between the bend relief and the outflow graft may have led to concentration of the twisting at one point, with the onset of clinically evident stenosis.

The CT scan did not differentiate between thrombotic mass and twisting, whereas in retrospect the sandglass-like form of the stenosis on CT scan and the angiogram showing the typical double contour of the twisted graft wall during the stenting might have led to the appropriate diagnosis. Unfortunately, the late onset of the symptoms led to a false interpretation of the findings. Only the lack of effect and the motion of the stenosis toward the pump prompted the correct diagnosis and appropriate treatment: surgical revision of the graft position.

To avoid the complication, we recommend paying close attention to the intraoperative positioning of the outflow graft before attaching the bend relief after the aortic anastomosis and apical connection have been completed. It would be helpful if the company would add two radiopaque lines along the graft to aid diagnosis and make changes to avoid any rotation of the graft after the nut has been secured.

After the proper diagnosis of twisting was established and thrombus inside the graft was ruled out, the surgeon assumed that graft rotation would not cause systemic embolization and carried less risk for bleeding than full resternotomy and the use of cardiopulmonary bypass for outflow graft replacement.

Meanwhile, very similar complications, with the same direction of graft rotation, have been diagnosed at our institution and treated as described above in 2 more patients 20 and 11 months, respectively, after HeartMate 3 implantation.

\section{CONCLUSIONS}

The CT scan should be used as a screening tool to detect pre- or postpump obstruction, ${ }^{4}$ and the angiogram should be used to verify the diagnosis. The sandglass form of the stenosis and the double contour of the graft wall at the narrow point, as seen in the angiogram, diagnosed the graft twisting. In this case, surgical revision is the only solution.

The authors thank Anne Gale for editorial assistance.

\section{References}

1. Pieri M, Scandroglio AM, Kukucka M, Kretzschmar A, Dreysse S, Falk V, et al Heart failure after 5 years on LVAD: diagnosis and treatment of out-flow graft obstruction. ASAIO J. 2016;63:e1-2.

2. Scandroglio AM, Kaufmann F, Pieri M, Kretzschmar A, Muller M Pergantis P, et al. Diagnosis and treatment algorithm for blood flow obstructions in patients with left ventricular assist device. J Am Coll Cardiol. 2016; 67:2758-68.

3. Potapov EV, Krabatsch T, Buz S, Falk V, Kempfert J. Cerebral protection system applied during washout of thrombus occluding inflow cannula of HeartWare HVAD left ventricular assist device. J Heart Lung Transplant. 2015;34:1640-1.

4. Tran BC, Nijjar PS. Role of contrast CT for the diagnosis and the prognosis of suspected LVAD thrombosis. J Card Surg. 2017;32:162-5. 